\title{
Optimization of Shielded PCB Air-Core Toroids for High-Efficiency DC-DC Converters
}

\author{
Stefano Orlandi, Bruno Andre Allongue, Georges Blanchot, Simone Buso, Member, IEEE, \\ Federico Faccio, Member, IEEE, Cristian Alejandro Fuentes, Maher Kayal, Member, IEEE, \\ Stefano Michelis, Member, IEEE, and Giorgio Spiazzi, Member, IEEE
}

\begin{abstract}
The paper describes the design of optimized printed circuit board (PCB) air-core toroids for high-frequency dc-dc converters with strict requirements in terms of volume and noise. The effect of several design parameters on the overall inductor volume, on dc and ac winding resistance, and on the radiated noise will be investigated. PCB toroids are compared to standard air-core solenoids and other state-of-the-art air-core toroids both theoretically and experimentally: at first, using ANSOFT Maxwell and ANSOFT Q3D simulation tools, and subsequently, with laboratory measurements (irradiated noise, efficiency, and frequency response) on several prototypes. These very flexible and rather easy to manufacture inductors appear very attractive for compact highfrequency dc-dc converters where high efficiency, low volume, and low noise are of primary concern.
\end{abstract}

Index Terms-Air-core inductors, dc-dc converters, electromagnetic interference reduction, magnetic shielding, printed circuit board (PCB) inductors.

\section{INTRODUCTION}

I N high-energy physics as well as in space applications, power supply designers have to face specific and uncommon constraints that prevent the use of standard solutions for switching devices and magnetic structures [1]. For instance, the presence of a 4-T dc magnetic induction in the physics experiments at the Large Hadron Collider (LHC) forces the power supply de-

Manuscript received April 26, 2010; revised August 18, 2010; accepted October 18, 2010. Date of current version August 5, 2011. The work of S. Michelis was supported by a Marie Curie Early Stage Research Training of the European Community's 6th Framework Program under Contract MEST-CT2005-020216-Elacco. The work of C. Fuentes was supported by the MECESUPChile under Grant FSM0601. Recommended for publication by Associate Editor B. Ferreira.

S. Orlandi, B. A. Allongue, G. Blanchot, and F. Faccio are with the CERN, Geneva 23, Switzerland (e-mail: stefano.orlandi@cern.ch; bruno-andre.allongue@cern.ch; georges.blanchot@cern.ch; federico.faccio@ cern.ch).

S. Buso is with the Department of Technical Management of Industrial Systems, University of Padova, 36100 Vicenza, Italy (e-mail: simone. buso@dei.unipd.it).

C. A. Fuentes is with CERN, Geneva 23, Switzerland, and also with UTFSM, 2340000 Valparaiso, Chile (e-mail: cristian.alejandro.fuentes.rojas@ cern.ch).

M. Kayal is with EPFL, Lausanne, Switzerland (e-mail: maher.kayal@ epfl.ch).

S. Michelis is with CERN, Geneva 23, Switzerland, and also with the École Polytechnique Fédérale de Lausanne, Lausanne 1015, Switzerland (e-mail: stefano.michelis@cern.ch).

G. Spiazzi is with the Department of Information Engineering, University of Padova, Padova 35131, Italy (e-mail: spiazzi@ dei.unipd.it).

Color versions of one or more of the figures in this paper are available online at http://ieeexplore.ieee.org

Digital Object Identifier 10.1109/TPEL.2010.2090902

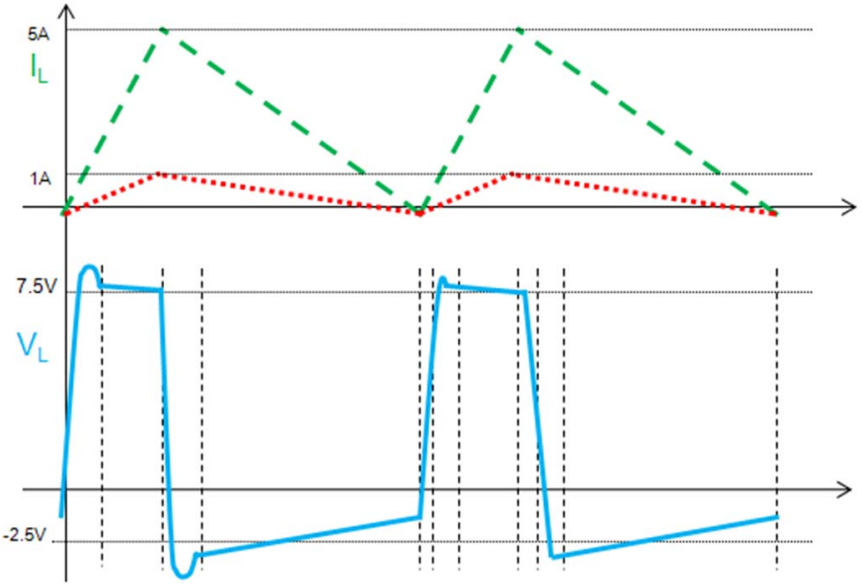

Fig. 1. Inductor current for the $1 \mathrm{~W}$ (dotted curve) and $6 \mathrm{~W}$ (dashed curve) buck converter. The blue curve on the bottom represents the voltage across the inductor for a buck converter with $2.5 \mathrm{~V}$ output voltage.

signers to adopt core-less inductors. On the other hand, the necessity of placing these components in point-of-load converters does not allow moving them to low magnetic field region. High level of integration, strict material budget, and low levels of electromagnetic irradiation are other typical constraints of such applications, having to be traded off with the necessity of high-efficiency components (low ohmic losses). In addition, considering a rather big production volume, these components must comply with standard industrialization processes in order to simplify the manufacturing operations, reduce the costs, and guarantee adequate levels of yield and performance.

In relation to these specific requirements, printed circuit board (PCB) air-core toroids are proposed to manufacture inductors of a few hundred nanohertz, operating at a switching frequency of 1-2 MHz and carrying triangular current waveforms with an average value between 1 and $3 \mathrm{~A}$. The target application is the use in buck-type converters in the range of $1-6 \mathrm{~W}$ of output power (see Fig. 1). Since these converters are supposed to work in quasi-square-wave conduction mode [2], the current ripple is, at least, twice the average value; therefore, considerable rms values are expected both for low- and high-frequency current components. Converter efficiency above $85 \%$ is expected for the application of our interest.

More in detail, Allongue et al. [1] show that the inefficiencies of the converter are mainly due to two factors: the switching losses of the power MOSFETs and the conduction losses of the inductor. The latter depend, at low frequency, on the dc current 
flowing through the dc resistance of the inductor, while at high frequency, on the rms value of the current flowing through the ac resistance of the coil, which is calculated, as an approximation, in correspondence to the switching frequency $(1 \mathrm{MHz})$. Therefore, considering the characteristics of the application of our interest, dc and ac resistances (and thus, the $Q$ factor) will be used throughout the paper to quantify the power efficiency of the inductors.

Optimal containment of the main flux inside the inductor, simple fabrication process (including the possibility to easily add an extra magnetic shield layer), small volume occupation, and low power loss are the key features of the toroids on PCB, outperforming in several aspects widely used commercial components (as RF air-core solenoids) or other proposed air-core inductor designs, as those in [3]-[7]. For what concerns the latter designs, air-core toroids presented in [3] and [4] seem to be suitable only for very high frequencies $(>30 \mathrm{MHz})$ and require a larger volume for the integration of hundreds of $\mathrm{nH}$. Planar inductors described in [5]-[7], instead, show evident drawbacks for the application of our interest, especially in terms of electromagnetic emission and power consumption. Finally, magnetic components have already been presented with implementations on PCB but more usually with ferromagnetic cores [8], [9], thus not suitable for the application of our interest. On the other hand, RF air-core solenoids represent the most widespread solution for the applications of our interest, because of the wide range of manufacturers available on the marketplace, and because their structure (already optimized) ensures good performances in terms of efficiency and overall compactness. For these reasons, RF air-core solenoids can be considered as a good benchmark to evaluate the performance of new PCB aircore toroids. Key parameters for this comparison are achievable values of inductance, dc and ac resistances, electromagnetic irradiation, volume occupation, and effective implementation (use of a qualified industrialization process).

The electromagnetic characterization of the inductors has been performed with ANSOFT Maxwell 3D v11.1 and ANSOFT Q3D Extractor, two software tools using the finite element method analysis to simulate and solve 3-D electromagnetic field problems. Given a defined geometry, these tools can also provide values of auto-inductance and dc/ac resistance. Aiming at a validation of the theoretical results, a first series of PCB air-core inductors has been manufactured, tested, and compared with the RF air-core solenoids. Even in this case, measurements have dealt with the values of inductance, winding resistance, and external magnetic irradiation. Particular attention has been reserved to the evaluation of the effects introduced by parasitic elements like the equivalent series resistance and the stray capacitances.

\section{RF AIR-CORE SOLENOID}

The RF air-core solenoid used as a benchmark (see Fig. 2) is a ten-turn inductor with a turn diameter equal to $3.8 \mathrm{~mm}$ and a wire radius of $0.19 \mathrm{~mm}$. The overall length is $8 \mathrm{~mm}$ and the material used is copper.

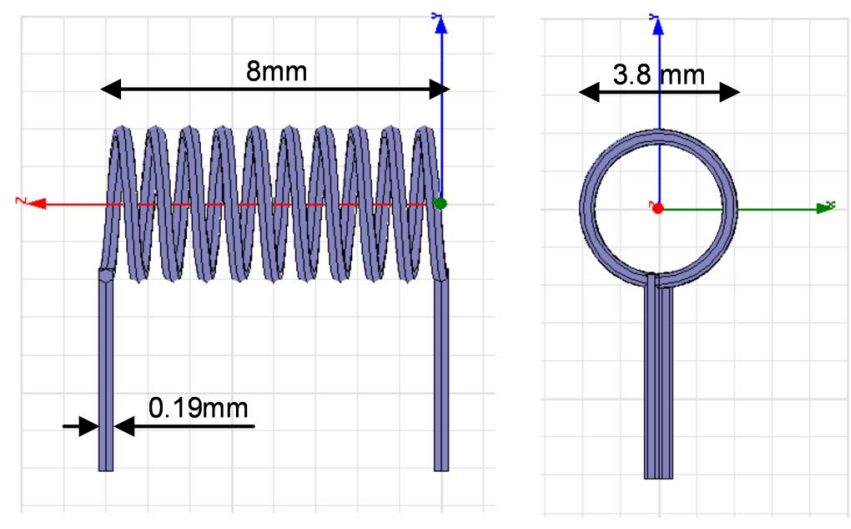

Fig. 2. 150-nH RF air-core solenoid under test.

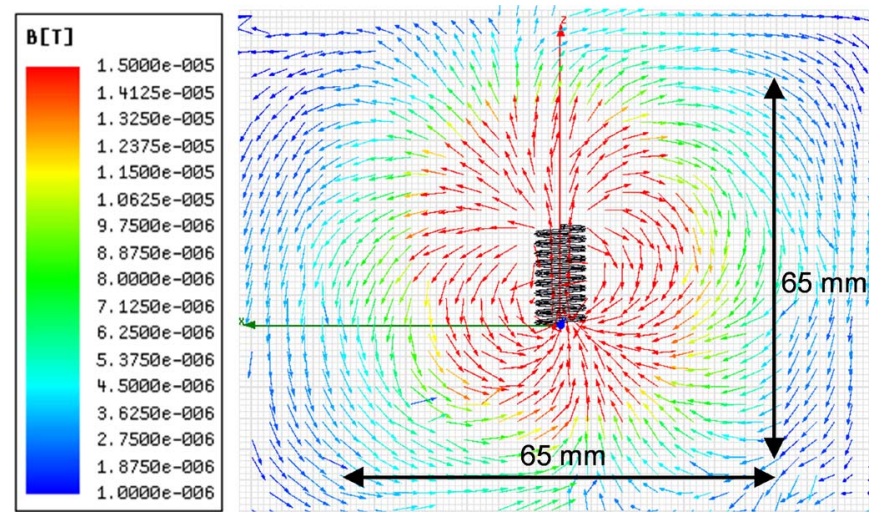

Fig. 3. Magnetic induction of the air-core solenoid, vector plot (each square side is $0.5 \mathrm{~mm}$ long). Relevant levels of magnetic induction are present even a few centimeters far from the inductor.

The nominal value of the inductance is $150 \mathrm{nH}$, chosen on purpose for a hypothetical converter providing $0.5 \mathrm{~A}$ to the output (dc), hence with a maximum current of $1 \mathrm{~A}$. The geometry selected for this sample reflects what proposed by Coilcraft for its "Fixed RF inductors-132 Series" nevertheless, in order to reduce simulation analysis time, it has been necessary to slightly modify some parameters, such as the turn pitch and the wire cross-section shape.

\section{A. Characterization of the Magnetic Field Emission}

A first useful exercise to characterize such an inductor is the evaluation of its magnetic field emission; for this purpose, radiation diagrams, taken after the simulations, are proposed in the next figures. These images refer to the condition where the current reaches the peak value of $1 \mathrm{~A}$, corresponding to the maximum irradiation level (worst case evaluation). The range of values indicated by the color code is $1-15 \mu \mathrm{T}$; this range allows us to study magnetic flux lines relatively far from the inductor (a few centimeters) but characterized by magnetic induction levels sufficient to radiate effectively the surrounding area, potentially adversely affecting other equipment placed nearby. Looking in Figs. 3 and 4, it is immediately clear that the main part of the magnetic field (and hence the energy managed by the inductor) 


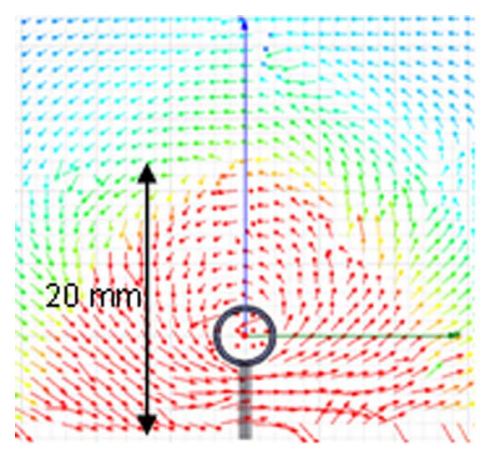

Fig. 4. Frontal view of the magnetic induction, vector plot (each square side is $0.5 \mathrm{~mm}$ long). For these levels of magnetic induction, even the effect of the terminals becomes non-negligible.

is not only concentrated inside the coil but also all around it, with non-negligible levels within $3 \mathrm{~cm}$ in all directions.

Moreover, an attentive analysis of the frontal view of the solenoid on the $X Y$-plane (see Fig. 4) suggests that the whole emission is not only related to the "conventional" contribution of the inductor; there is also a "parasitic" contribution, perpendicular to the former, due to the "semiloop" performed by the inductor and its two terminals. Clearly, this contribution is marginal if compared with the induction level inside the solenoid; nevertheless, considering flux lines a few centimeters far from the inductor with order of magnitude $10^{-5}$ to $10^{-6} \mathrm{~T}$, the two effects become absolutely comparable. This last evaluation suggests the following consideration: although it is important to reduce as much as possible the external irradiation generated by these magnetic components, a minimum level of irradiation has to be tolerated, and this level is represented by the irradiation of a single piece of wire carrying the same current of the inductor under test. This minimum level of magnetic field density, estimated around $1 \mu \mathrm{T}$, can be used as a "safety threshold" to determine whether a certain component is a dangerous source of noise, establishing at the same time a goal for potential actions that aim at a reduction of the external magnetic irradiation. In order to obtain a more precise measurement of the induction level along the main axis of the solenoid ( $Z$-axis), Fig. 5 shows its trend from the middle of the coil to a distance of $18 \mathrm{~mm}$ (the first $4 \mathrm{~mm}$ is still inside the solenoid; in fact, the induction value is roughly constant and starts to decrease close to the last turns). The theoretical formula for the induction along the $Z$ axis, which represents the solution of the Maxwell equation for a simple and well-defined condition, can be written as

$B(x)=\frac{\mu_{0} N I}{2 d}\left[\frac{d+2 x}{\sqrt{(d+2 x)^{2}+4 R^{2}}}+\frac{d-2 x}{\sqrt{(d-2 x)^{2}+4 R^{2}}}\right]$

where $\mu_{0}$ is the magnetic permeability of the air, $N$ the number of turns, $I$ the current flowing into the winding, $d$ the length of the solenoid, $R$ the radius of the solenoid, and $x$ is the distance (along $Z$-axis) between the middle of the solenoid and the measurement point. The comparison of the results of (1) and of the simulation (see Fig. 5) evidences a good matching: Ansoft Maxwell correctly reproduces the theoretical behavior of the magnetic field emission, especially inside the solenoid where

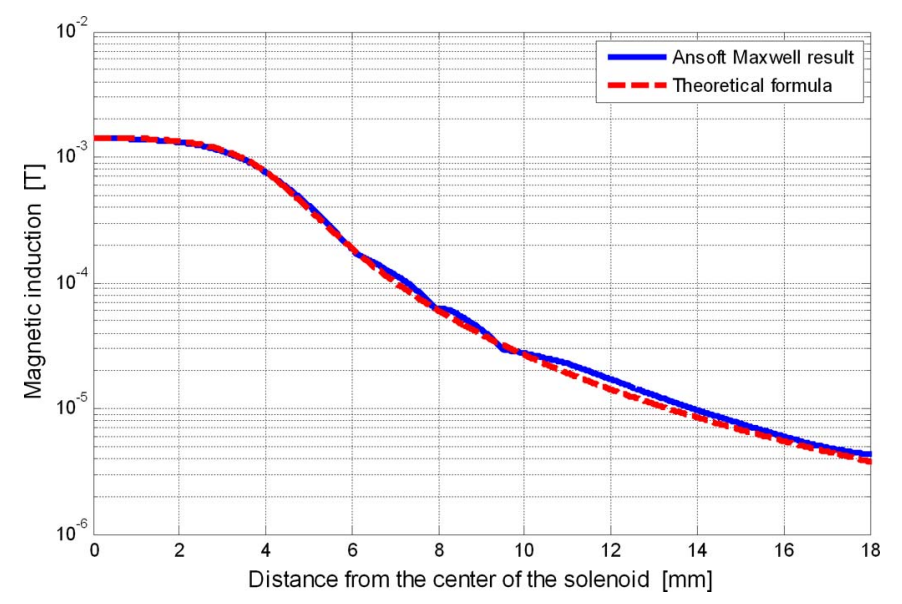

Fig. 5. Magnetic field induction along $Z$-axis processed by Ansoft Maxwell (solid curve) in comparison with the correspondent theoretical formula (dotted curve). First $4 \mathrm{~mm}$ are inside the solenoid.

the induction level is quite high and, therefore, the incidence of the mathematical approximations is almost negligible.

\section{B. Electrical Performances}

As expected, this type of inductor shows excellent electrical performance: values estimated by Ansoft Q3D for the dc and high-frequency $(1 \mathrm{MHz})$ resistance are, respectively, 23.5 and $41.4 \mathrm{~m} \Omega$, leading to a quality factor of 22.8 . Thanks to its optimized geometry, the increase of the resistance at high frequency due to skin and proximity effects is rather small.

\section{Shielding}

The main drawback of such inductors for our application is the relatively intense emission of magnetic field in the space surrounding it; emission that can influence the noise performance of electronics systems. One such example has been widely described in [10]: analyzing the conducted output noise of a dc-dc converter prototype which was equipped with a 500-nH aircore solenoid, we saw that the noise was very sensitive to the orientation of the inductor. Changing orientation modifies the magnetic flux in sensitive loops of the converter, with a significant increase of the conducted output noise (up to $+20 \mathrm{~dB}$ on high-frequency components of the common mode current). This evidences that the level of emission from these RF solenoidal coils is sufficiently large to give measurable system effects. Low-noise applications need, therefore, magnetic components with properly confined emission; the simplest and most effective solution to achieve this goal is the adoption of shielding techniques. From Faraday-Lenz's law, the magnetic field irradiated by the coil induces eddy currents in a metallic shield placed nearby; the secondary magnetic field generated by such eddy currents opposes to the original one, leading to an overall reduction of the magnetic field beyond the shield. Critical parameters that define the effectiveness of the shield are its geometry and its resistivity, and it should also be considered that a shield positioned too close to the inductor might modify its inductance value. Simulations with Ansoft software tools have 


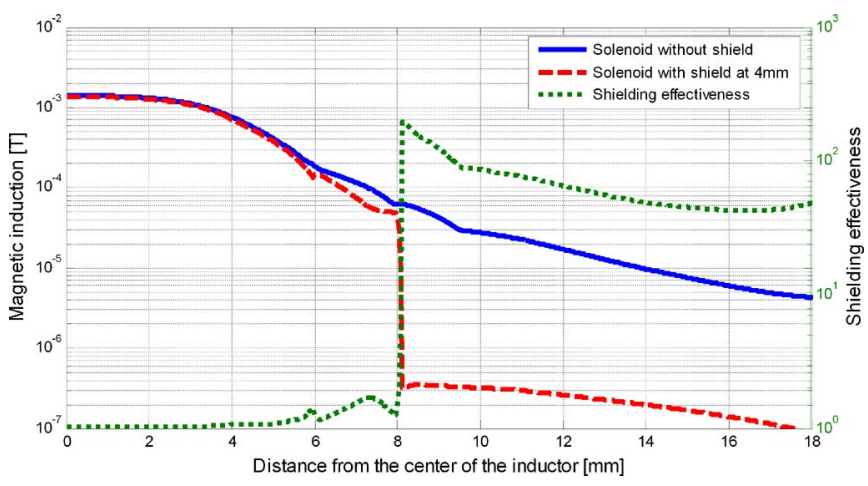

Fig. 6. Magnetic induction along the $Z$-axis of the solenoid without shield (solid curve) and with shield (dashed curve); first $4 \mathrm{~mm}$ are inside the solenoid. With the shield, the external irradiation is well below the safety limit of $1 \mu \mathrm{T}$. The performance of the shield can be also evaluated through the shielding effectiveness (dotted curve).

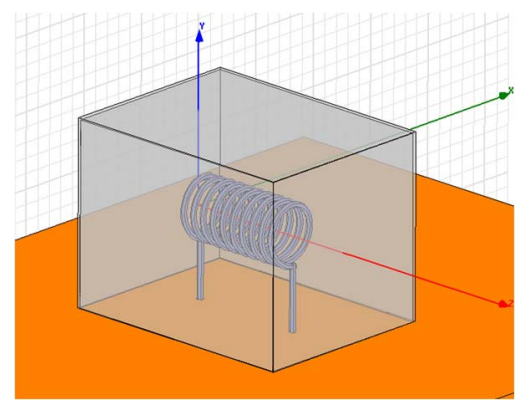

Fig. 7. RF air-core solenoid under test with aluminum shield. The volume increase by a factor 9 is due to the necessity of reducing the noise emission without affecting the inductance value.

shown that a $100-\mu \mathrm{m}$ aluminum foil wrapped all around the solenoid, at a distance of only $0.4 \mathrm{~mm}$, reduces quite well the emitted magnetic field but also decreases the inductance value from 150 to $111 \mathrm{nH}(-26 \%)$. Following an empirical law [11], the same aluminum foil shield has been put at a distance equal to the solenoid diameter (around $4 \mathrm{~mm}$ ). This provision reduces the irradiation relatively far from the inductor, without affecting those components defining the main part of the energy stored by the coil (see Fig. 6). The same result can be seen in terms of shielding effectiveness [12], which is the ratio between the field strength, at a given distance from the source, without the shield interposed and the field strength with the shield interposed. The dotted curve in Fig. 6 shows that a shielding effectiveness beyond $40(32 \mathrm{~dB})$ is achieved, with a peak of $200(46 \mathrm{~dB})$ nearby the shield aluminum box.

Although the irradiation problem is now evidently solved, the volume of the device is considerably increased: for an $8-\mathrm{mm}$ long solenoid with a $3.8-\mathrm{mm}$ diameter, located $4 \mathrm{~mm}$ above the ground plane, the shielded configuration reaches a length of $16 \mathrm{~mm}$, a width of $12 \mathrm{~mm}$, and a height of at least $12 \mathrm{~mm}$ (see Fig. 7); this means a volume increase by a factor 9 . Furthermore, the construction of such a structure is not straightforward without the addition of even more material to guarantee sufficient stability and robustness.

As a further demonstration of the need for a shield and its effectiveness in low-noise applications, Fig. 8 shows the effect of

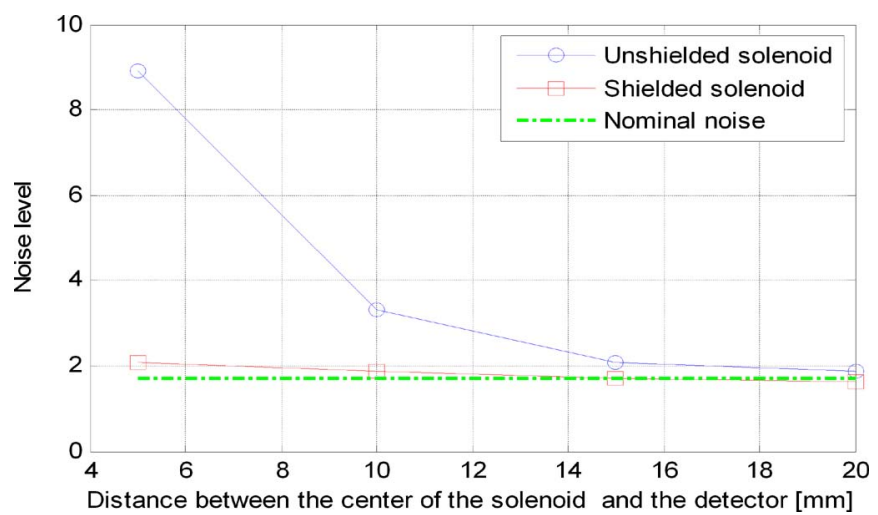

Fig. 8. Effect of the shielding on a typical front-end system of LHC detectors. The noise level is defined as the number of fake particles detected by the read-out circuitry when no inputs are applied to the system.

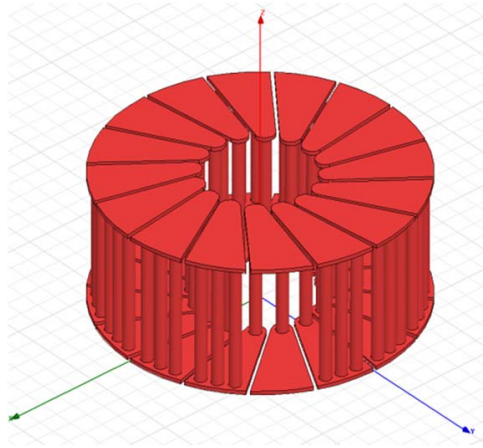

Fig. 9. 3-D image of a $150 \mathrm{nH} \mathrm{PCB}$ air-core toroid.

a 500-nH air-core solenoid (with the same excitation mentioned previously, hence a sinusoidal current of $1 \mathrm{~A}$ peak at a frequency of $1 \mathrm{MHz}$ ) on a typical front-end system in LHC detectors [13].

This system is made up by a silicon strip detector module whose signal is read out (amplified, compared to a threshold, stored in memory) by a custom ASIC. For this kind of systems, the noise level is defined as the number of fake particles detected when no input is applied to the read-out circuitry. The system noise is considerably increased over its nominal value by the electromagnetic emission from the solenoid placed close to the detector. A 50- $\mu \mathrm{m}$ aluminum shield, wrapped all around the solenoid, reduces the emission, and the system noise is kept to its nominal level.

\section{PCB AIR-CORE TOROID}

In view of the difficulties in properly shielding a solenoid inductor in a compact device, a new design for air-core PCB toroids is proposed. Fig. 9 shows such a design for a $150-\mathrm{nH}$ inductor that yields electric performance comparable to those of the solenoid but with a containment of the magnetic field that can be more easily achieved without volume increase, addition of material, or manufacturing complications. Table I provides the geometrical and electrical characteristics of such an inductor.

Similar to what adopted in [14], the structure of these PCB inductors is composed by two copper layers placed at large distance (typically $3.2 \mathrm{~mm}$ ), properly connected through a number 
TABLE I

GeOMEtrical and EleCtrical Characteristics PREDICTED WITH ANSOFT Q3D

\begin{tabular}{ll}
\hline Effective inductance & $150 \mathrm{nH}$ \\
Number of turns & 16 \\
External diameter & $7.8 \mathrm{~mm}$ \\
Total height & $3.4 \mathrm{~mm}$ \\
Total volume & $162 \mathrm{~mm}^{3}$ \\
DC resistance & $30 \mathrm{~m} \Omega(\mathrm{Cu}$ filled vias) \\
AC resistance $(@ 1 \mathrm{MHz})$ & $54 \mathrm{~m} \Omega(\mathrm{Cu}$ filled vias) \\
\hline
\end{tabular}

of vias. The support material can be the commonly used FR4, which has negligible magnetic properties. Each of the two copper layers is patterned in "petals." The current enters from the top metal line, crosses the corresponding top petal, and reaches the bottom one through one via at the inner end of the petal. The outer end of this petal is aligned with the second petal on the top layer; the connection is again assured by several vias at the outer side. In this way, the current has circulated in a loop. This structure is repeated along the whole toroid, which is in fact a series of current loops around a circumference in the middle of the petals. The area of each loop and the number of loops determine the total inductance.

The fabrication process for this kind of structure is rather simple: the upper and lower petals are directly printed on the two sides of a PCB and the connection between them is performed with common vias. This inductor could, in principle, be realized directly on the same PCB of the converter; alternatively, it is possible to choose the optimized characteristics for the PCB process (thickness of FR4 and copper, central hole and via dimension, etc.) and produce stand-alone toroids, which can be mounted on the converter PCB. In this case, each inductor can be optimized to the specific application: different designs, minimizing different characteristics [equivalent series resistance (ESR), size], can be manufactured with the same process.

\section{A. Characterization of the Magnetic Field Emission}

Thanks to the toroidal geometry, the main flux of the inductor is well contained inside the coil and, more precisely, concentrated in the inner part of the toroid. Nevertheless, considering the magnetic field density values we are interested in $(1-15 \mu \mathrm{T})$, the main concern in terms of external irradiation is no longer the internal flux but the parasitic one through the central hole of the coil (irradiation due to the current flux along the single-turn loop around the central hole of the toroid). As shown in Fig. 10, these parasitic flux components can easily exceed the threshold value of $1 \mu \mathrm{T}$. Unlike the magnetic field of the solenoid, this is a parasitic magnetic field; neither it determines the amount of energy stored inside the inductor, nor it determines the inductance value. Therefore, it can be shielded without any performance degradation or further volume consumption. In this scenario, a PCB air-core toroid can be shielded in a really easy and efficient way. The shield, in fact, can be applied as an extra copper layer, directly above and below the inductor, at a distance of a few hundred micrometers, without affecting the inductance value of the toroid (see Fig. 11). As shown in Fig. 12, the magnetic
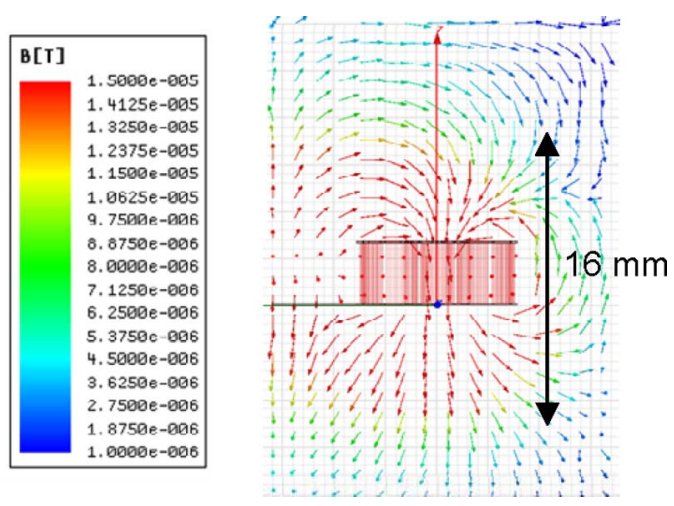

Fig. 10. Parasitic magnetic field induction of a 150-nH PCB toroid (vector plot). This is the parasitic effect of the current flowing along the single-turn-loop performed by the toroid.

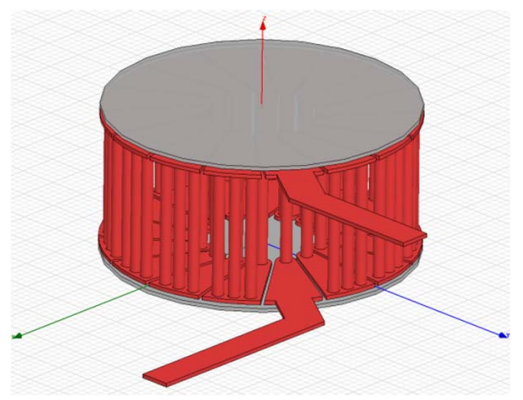

Fig. 11. Shielded $150 \mathrm{nH}$ PCB air-core toroid (the 100- $\mu$ m-thick shielding layers are placed $100 \mu \mathrm{m}$ far from the petals layer).

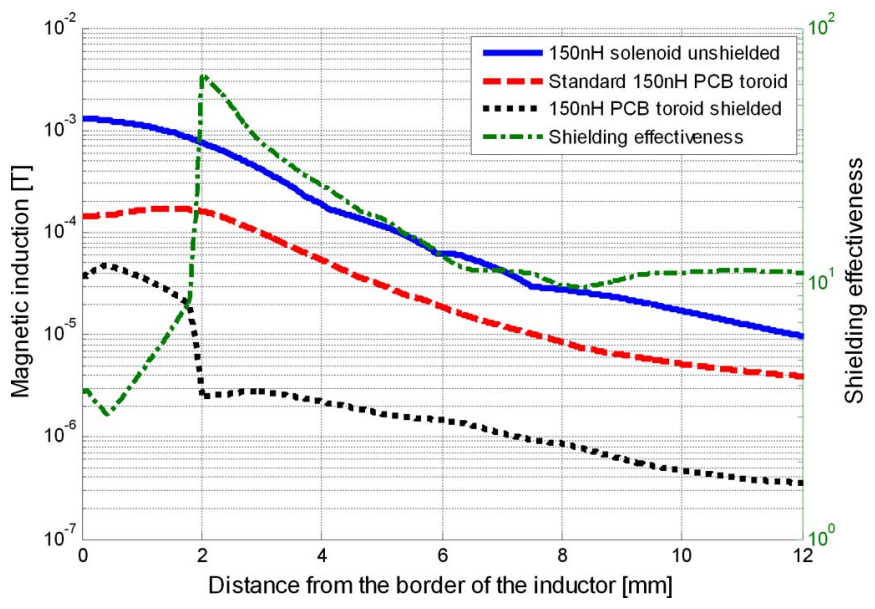

Fig. 12. Comparison of the simulated magnetic induction along the $Z$-axis of the inductors. Unshielded solenoid (solid curve), unshielded PCB toroid (dashed curve), and shielded PCB toroid (dotted curve). The dotted/dashed curve represents the shielding effectiveness of the two extra layers.

induction along the PCB toroid $Z$-axis (lower than the one of the solenoid even without any shield) is further reduced by a factor 10 simply adding two $100 \mu \mathrm{m}$ shielding layers just above and below the toroid, reaching the "safety threshold" of $1 \mu \mathrm{T}$ within $7 \mathrm{~mm}$. Thus, for the application of interest, a shielding effectiveness between 10 and 70 can be considered more than enough. On top of that, since the shielding layers are put at a 
TABLE II

DimENSIONS COMPARISON BETWEEN PCB TOROID AND SOLENOID (SHIELDED AND UNSHIELDED)

\begin{tabular}{lccccc}
\hline & PCB toroid & Shielded PCB toroid & Standard solenoid & $\begin{array}{c}\text { Standard solenoid } \\
\text { with far shield }\end{array}$ & $\begin{array}{l}\text { Standard solenoid } \\
\text { with close shield }\end{array}$ \\
\hline Predicted inductance & $150 \mathrm{nH}$ & $148 \mathrm{nH}$ & $150 \mathrm{nH}$ & $150 \mathrm{nH}$ & $111 \mathrm{nH}$ \\
Number of turns & 16 & 16 & 10 & 10 & 10 \\
External diameter & $7.8 \mathrm{~mm}$ & $7.8 \mathrm{~mm}$ & -- & -- & $9 \mathrm{~mm}$ \\
Total width & -- & -- & $8 \mathrm{~mm}$ & $16 \mathrm{~mm}$ & $5 \mathrm{~mm}$ \\
Total height & -- & -- & $3.8 \mathrm{~mm}$ & $12 \mathrm{~mm}$ & $9 \mathrm{~mm}$ \\
Total height & $3.4 \mathrm{~mm}$ & $3.8 \mathrm{~mm}$ & $8 \mathrm{~mm}$ & $12 \mathrm{~mm}$ & $405 \mathrm{~mm}^{3}$ \\
Total volume & $162 \mathrm{~mm}^{3}$ & $182 \mathrm{~mm}^{3}$ & $243 \mathrm{~mm}^{3}$ & $2304 \mathrm{~mm}^{3}$ & \\
\hline
\end{tabular}

distance of only $100 \mu \mathrm{m}$, the whole structure shows a negligible increase in the overall volume (see Table II).

\section{B. Electrical Performances}

If smaller field emission is the key feature of the PCB air-core toroids, even electrical performances have shown to be competitive with those of standard air-core solenoids. For the sample previously shown in Fig. 9, Ansoft Q3D estimates a dc resistance of $30 \mathrm{~m} \Omega$ and an ac resistance at $1 \mathrm{MHz}$ equals to $54 \mathrm{~m} \Omega$ (after the manufacturing process, these values will be slightly higher because of the addition of the inductors terminals). These levels of resistance are achievable with the use of vias filled with copper, since a large contribution to the resistance is given by the single via connecting two petals toward the center of the toroid. With standard vias (only a few tens of micrometers of copper), a higher resistance value can be expected: for instance, an increase of a factor 2.7 is estimated by Ansoft Q3D in the case of vias with internal copper thickness of $50 \mu \mathrm{m}$. In addition, the use of rather thin copper layers for the petals $(100 \mu \mathrm{m})$ ensures sufficiently low dc resistance without a strong increase at high frequency (at $1 \mathrm{MHz}$, the skin depth is $67 \mu \mathrm{m}$; therefore, the effective surface of copper carrying the current does not decrease excessively). Of course, these performances cannot be as competitive as those of state-of-the-art conventional inductors that use magnetic core [15], [16], where dc/ac resistances of a few milliohms can be easily achieved for RF inductors around $150-200 \mathrm{nH}$. Nevertheless, the impossibility of withstanding 4T dc magnetic fields does not allow considering their adoption for the application of our interest.

Thanks to the high flexibility guaranteed by these full custom components, the geometry of the toroids can be easily rearranged in order to obtain a strong reduction either in the dc resistance or in the overall size. Because of the many parameters that affect the inductor performance, a mathematical model (written with Mathcad 14) has been developed to compare different geometries and indicate which one better complies with the requirements defined for each application. Such a model basically predicts inductance and resistance of the coil by analyzing the contribution of each elementary part, such as petals and vias. Geometrical dimensions, material, frequency, and temperature are the parameters taken into account. Calculating inductance and resistance as functions of such parameters, it has been possible to identify inductors' geometries which complied with the target of our application. After this initial step, anyway, more precise simulations have been performed with the Ansoft

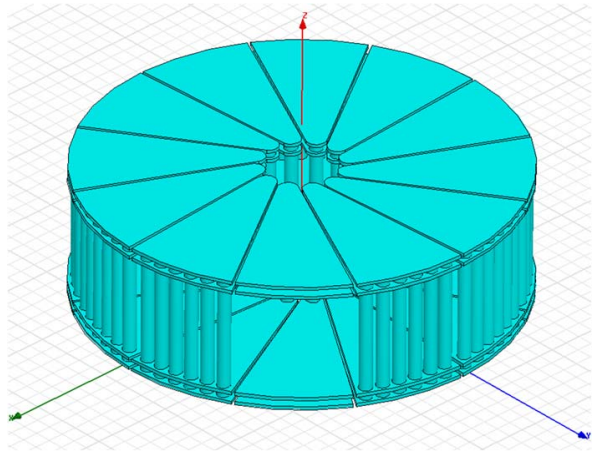

Fig. 13. $150 \mathrm{nH}$ PCB toroid with extremely low dc and ac resistance. ESR reduction is achieved using bigger filled vias and two additional metal layers ("duplicating" each petal with a parallel structure).

TABLE III

COMPARISON BETWEEN PCB TOROIDS AND STANDARD SOLENOIDS

\begin{tabular}{lccc}
\hline & $\begin{array}{c}\text { Small size } \\
\text { PCB toroid }\end{array}$ & $\begin{array}{c}\text { Low ESR } \\
\text { PCB toroid }\end{array}$ & $\begin{array}{c}\text { Standard } \\
\text { solenoid }\end{array}$ \\
\hline Inductance & $150 \mathrm{nH}$ & $149 \mathrm{nH}$ & $150 \mathrm{nH}$ \\
N. of turns & 16 & 12 & 10 \\
Dimensions & $7.8 \mathrm{~mm} \times 3.4 \mathrm{~mm}$ & $13 \mathrm{~mm} \times 4 \mathrm{~mm}$ & $8 \mathrm{~mm} \times 4 \mathrm{~mm} \times 4 \mathrm{~mm}$ \\
DC resistance & $30 \mathrm{~m} \Omega$ & $12.7 \mathrm{~m} \Omega$ & $23.5 \mathrm{~m} \Omega$ \\
AC resistance* & $54 \mathrm{~m} \Omega$ & $42.3 \mathrm{~m} \Omega$ & $41.4 \mathrm{~m} \Omega$ \\
Quality factor & 17.3 & 22.1 & 22.8 \\
\hline & Shielded small & Shielded low & Standard solenoid \\
& size PCB toroid & ESR PCB toroid & with close shield \\
\hline Inductance & $148 \mathrm{nH}$ & $148 \mathrm{nH}$ & $111 \mathrm{nH}$ \\
N. of turns & 16 & 12 & 10 \\
Dimensions & $7.8 \mathrm{~mm} \times 3.8 \mathrm{~mm}$ & $13 \mathrm{~mm} \times 4.4 \mathrm{~mm}$ & $9 \mathrm{~mm} \times 5 \mathrm{~mm} \times 9 \mathrm{~mm}$ \\
DC resistance & $30 \mathrm{~m} \Omega$ & $12.7 \mathrm{~m} \Omega$ & $23.5 \mathrm{~m} \Omega$ \\
AC resistance* & $54 \mathrm{~m} \Omega$ & $49 \mathrm{~m} \Omega$ & $49.3 \mathrm{~m} \Omega$ \\
Quality factor & 17.2 & 19 & 14.1 \\
\hline *estimated at $1 \mathrm{MHz}$ & & &
\end{tabular}

estimated at $1 \mathrm{MHz}$

software tools, yielding all parameters for the design. Following this procedure, another sample of $150 \mathrm{nH}$ PCB toroid has been designed with $R_{\mathrm{dc}}$ and $R_{\mathrm{ac}}$ (at $1 \mathrm{MHz}$ ) equal to 12.7 and $42.3 \mathrm{~m} \Omega$, respectively (see Fig. 13).

This has been possible by adopting filled vias with bigger diameter and a double layer for the petals. On the other hand, these modifications need larger dimensions; this specific sample, for instance, has an overall diameter equal to $13 \mathrm{~mm}$. Table III summarizes the geometrical and electrical characteristics of PCB toroids designed with different targets: low ESR or reduced volume consumption. A comparison with standard air-core solenoids shows a substantial uniformity in terms of electrical performance (not evidenced in this table, the emission 


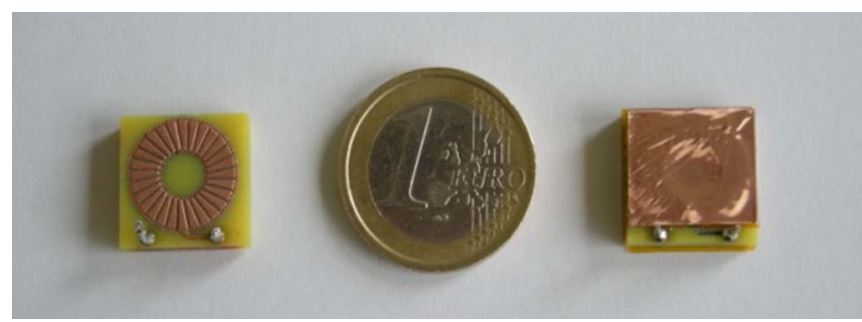

Fig. 14. Prototypes of $500 \mathrm{nH}$ PCB air-core toroid without and with shield.

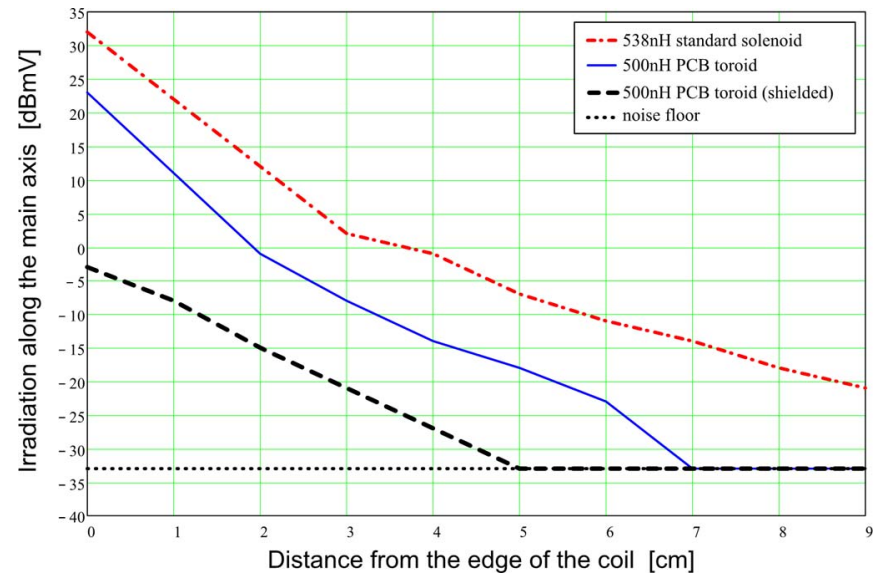

Fig. 15. Measurement of the magnetic induction along the main axis of the inductors. $538 \mathrm{nH}$ solenoid (dotted/dashed curve), $500 \mathrm{nH}$ PCB toroid (solid curve), and shielded $500 \mathrm{nH}$ PCB toroid (dashed curve).

from the standard solenoid cannot be shielded without considerable penalty in volume).

\section{Measurements Results}

After the design phase, a series of PCB air-core toroids was scheduled for a first prototype run. Inductors with different inductance value, dimensions and electrical performances have been produced and tested at CERN. To simplify the manufacturing process, prototypes have been realized with partially filled vias. The consequent increase of the ESR has been partially reduced implementing a double-petal structure (therefore, the toroids are built on a four-layer PCB). To avoid the production of too thick PCBs (at least for these first prototypes), the shield is added afterward applying a 100- $\mu$ m-thick copper tape above and below the coils (see Fig. 14).

Kapton tape is used to prevent shorts between metallic shield and petals. The evaluation of the magnetic emission of such inductors has been performed using near field magnetic probes connected to a spectrum analyzer, thus minimizing the perturbation of the coil irradiation (measurements are based on the current induced inside the magnetic field probe). The inductors chosen for the test are a-538 nH RF air-core solenoid (made by Coilcraft) and a 500-nH PCB air-core toroid, both of them supplied with a 1-MHz sinusoidal current having a peak value of 1 A. The irradiation patterns along the inductors' main axis reflect well enough what simulated by Ansoft Maxwell (see Fig. 15).

Looking at the external irradiation nearby the edge of the coils, the ratio between solenoid and toroid is around a factor 3 ,
TABLE IV

INDUCTANCE AND DC RESISTANCE OF THE PCB TOROIDS PROTOTYPES (Simulated AND MEASURED, With AND Without SHIELD)

\begin{tabular}{cccc}
\hline Inductor type & Simulation & $\begin{array}{c}\text { Measurement } \\
\text { unshielded }\end{array}$ & $\begin{array}{c}\text { Measurement } \\
\text { shielded }\end{array}$ \\
\hline $150 \mathrm{nH}$ & $149 \mathrm{nH}$ & $165 \mathrm{nH}$ & $160 \mathrm{nH}$ \\
(low size) & $70 \mathrm{~m} \Omega$ & $67 \mathrm{~m} \Omega$ & $67 \mathrm{~m} \Omega$ \\
\hline $150 \mathrm{nH}$ & $149 \mathrm{nH}$ & $180 \mathrm{nH}$ & $177 \mathrm{nH}$ \\
(low ESR) & $36 \mathrm{~m} \Omega$ & $45 \mathrm{~m} \Omega$ & $45 \mathrm{~m} \Omega$ \\
\hline \multirow{2}{*}{$350 \mathrm{nH}$} & $327 \mathrm{nH}$ & $344 \mathrm{nH}$ & $337 \mathrm{nH}$ \\
& $109 \mathrm{~m} \Omega$ & $102 \mathrm{~m} \Omega$ & $102 \mathrm{~m} \Omega$ \\
\hline \multirow{2}{*}{$500 \mathrm{nH}$} & $454 \mathrm{nH}$ & $480 \mathrm{nH}$ & $477 \mathrm{nH}$ \\
& $130 \mathrm{~m} \Omega$ & $139 \mathrm{~m} \Omega$ & $139 \mathrm{~m} \Omega$ \\
\hline
\end{tabular}

while the introduction of a shield decreases the irradiation of a further factor 20. The results of Ansoft Maxwell simulation in Fig. 12 confirm this trend, although the latter are associated with different values of inductance $(150 \mathrm{nH}$ instead of $500 \mathrm{nH})$. A similar correspondence is found moving the measurement point $1 \mathrm{~cm}$ far from the coils. Again, between solenoid and toroid, there is an irradiation reduction of factor 2; adding a $100-\mu \mathrm{m}-$ thick copper shield, the irradiation is reduced by a further order of magnitude (again well reflecting what simulated by Ansoft Maxwell). For what concerns the electrical performance, measurements carried out on the PCB air-core toroids showed good agreement with Ansoft Q3D simulations (see Table IV). The higher values of inductance in the measurements are due to the presence of the coil terminals, neglected during the simulations. Considering terminals of $1 \mathrm{~cm}$ with inductance of $1 \mathrm{nH} / \mathrm{mm}$, the difference between measurements and simulations can be well explained. Even for the dc resistance, there is good agreement. As expected, the presence of empty vias increases considerably the ESR with respect to the initial estimation (2.7 times the value with filled vias), leading to worse performance than those of the solenoids. Nevertheless, the mathematical model showed to be reliable; thus, we are confident that the initial predictions can also be met by inductors with filled vias. A last series of measurements deals with the evaluation of the frequency response of the PCB toroids. More in detail, toroidal inductors are known to present a relatively large parasitic capacitance, if compared to solenoidal ones [17]. On top of that, the addition of a shield could magnify such an effect by introducing a further contribution due to the turns-to-shield stray capacitances [18]. This is expected to lower the inductor resonance frequency and, ultimately, to limit its frequency range of operation. To quantify this effect, an experimental determination of the equivalent parasitic capacitance has been performed on a few toroidal inductors. Table V summarizes the results of such measurements. The test has been carried out by using an impedance analyzer with an internal tracking generator that can provide a sinusoidal signal of constant amplitude $(100 \mathrm{~dB} \cdot \mu \mathrm{V})$ up to a limit frequency of $1.5 \mathrm{GHz}$. Looking at the results of Table V, it is clear that the resonance frequencies are in any case relatively high, well above $100 \mathrm{MHz}$, which guarantees a proper inductive behavior for the switching frequencies of interest for the application (i.e., 1 or $2 \mathrm{MHz}$ ). As expected, the resonance frequency is related to the size of the toroid and to the presence of the shield. The shielded 
TABLE V

Measurements of Resonance Frequency and Parasitic Capacitance For a Few Types of Toroidal Inductors

\begin{tabular}{lccccc}
\hline Inductor type & $\begin{array}{c}\text { Inductance value } \\
\text { (nominal) }\end{array}$ & $\begin{array}{c}\text { Inductance } \\
\text { value @ } 1 \mathrm{MHz}\end{array}$ & $\begin{array}{c}\text { Inductance } \\
\text { value @ 2 } 2 \mathrm{MHz}\end{array}$ & $\begin{array}{c}\text { Measured } \\
\text { resonance frequency }\end{array}$ & $\begin{array}{c}\text { Estimated parasitic } \\
\text { capacitance }\end{array}$ \\
\hline PCB toroid & $150 \mathrm{nH}$ & $122 \mathrm{nH}$ & $119 \mathrm{nH}$ & $396 \mathrm{MHz}$ & $1.32 \mathrm{pF}$ \\
\hline PCB toroid & $350 \mathrm{nH}$ & $275 \mathrm{nH}$ & $270 \mathrm{nH}$ & $225 \mathrm{MHz}$ & $1.86 \mathrm{pF}$ \\
\hline Shielded PCB toroid & $500 \mathrm{nH}$ & $402 \mathrm{nH}$ & $396 \mathrm{nH}$ & $111 \mathrm{MHz}$ & $5.14 \mathrm{pF}$ \\
\hline Wound toroid & $300 \mathrm{nH}$ & $264 \mathrm{nH}$ & $260 \mathrm{nH}$ & $730 \mathrm{MHz}$ & $0.19 \mathrm{pF}$ \\
\hline
\end{tabular}

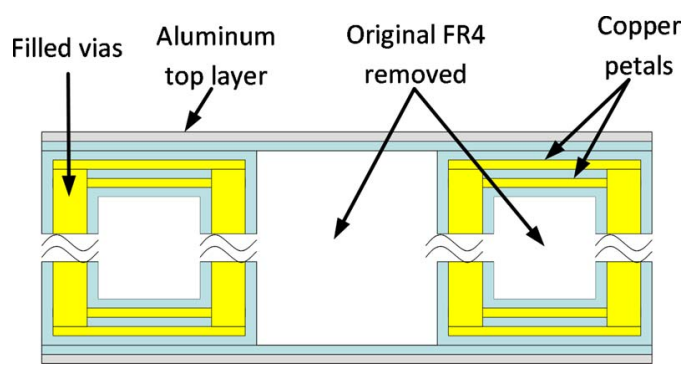

Fig. 16. Cross-section of the ideal PCB air-core toroid. Part of the internal FR4 could be removed to improve the material budget.

toroid indeed presents the minimum resonance frequency (i.e., the highest stray capacitance); instead, the wound toroid is the one with the highest resonance frequency (i.e., the minimum stray capacitance). A motivation for this result is the smaller interwinding capacitance of the wound inductor, whose turns are much more distant from each other than in a PCB toroid. Nevertheless, dealing with such high values of resonance frequency, even in the case of shielding adoption, PCB toroids can certainly be considered a valid solution for the application.

\section{Manufacturing Issues}

In view of the industrialization of the PCB air-core toroids, a market survey is being conducted to verify the opportunity of a large-scale manufacturing. Discussing directly with the producers, we would also be interested in exploring the possibility to remove part of the FR4 that forms the PCB (see Fig. 16); this is desirable in application where weight is a key parameter.

Moreover, the use of aluminum instead of copper would be preferable for the realization of the shield, to decrease the material budget, although it is important to assure a low enough resistivity of the shielding layers.

A last consideration deals with the fabrication parameters used for the design of the PCB toroids (layers thickness, separation between traces, $\mathrm{max} / \mathrm{min}$ via diameter, etc.). All of them are linked to the specific process chosen by each manufacturer [19]; therefore, the final aspect (and the performance) of the PCB toroids will have to be reviewed taking into account new constraints defined by the process flow used for the production.

\section{CONCLUSION}

New PCB air-core toroids have been proposed as an effective way to manufacture inductors with optimum performance in terms of dc/ac resistance, external irradiation, and volume occupation. RF air-core solenoids have been identified as a valid benchmark for an exhaustive comparison. Although those inductors have good electrical performance, theoretical and experimental evidence suggested that the emission from the solenoid has to be properly shielded for low-noise applications. Nevertheless, an efficient shield would strongly penalize the device in terms of volume, material budget, and process reliability.

PCB air-core inductors, instead, have revealed comparable electric performance with optimum levels of magnetic flux containment, compactness, and material consumption. Moreover, the flexibility of the manufacturing process allows the designer to optimize the coil for different applications, minimizing the size rather than the power losses. These conclusions are based, in a first stage, on simulations supported by benchmarking to analytical calculations; afterward, a series of PCB air-core toroids has been designed, produced, and tested. Prototypes' performances have shown good agreement with theoretical expectations, both in terms of external magnetic irradiation and of electric characteristics. Future activities will be focused on the individuation of a PCB manufacturer to finalize the design of the coils and evaluate the performance of the final product.

\section{ACKNOWLEDGMENT}

The authors would like to thank D. Cussans, University of Bristol, for his contribution for the profitable exchange of ideas during the early stages of this paper.

\section{REFERENCES}

[1] B. Allongue, G. Blanchot, C. Fuentes, F. Faccio, S. Michelis, S. Orlandi, P. Mattavelli, S. Buso, and G. Spiazzi, "Custom dc-dc converters for distributing power in SLHC trackers," in Proc. Topical Workshop Electron. Particle Phys. (TWEPP'08), 2011, pp. 289-293.

[2] D. Maksimovic, "Design of the zero-voltage-switching quasi-square-wave resonant switch," in Proc. Power Electron. Spec. Conf. (PESC), 1993, pp. 323-329.

[3] C. Sullivan, W. Li, S. Prabhakaran, and S. Lu, "Design and fabrication of low-loss toroidal air-core inductors," in Proc. Power Electron. Spec. Conf. (PESC), 2007, pp. 1754-1759.

[4] M. Nigam and C. Sullivan, "Multi-layer folded high-frequency toroidal inductor windings," in Proc. Appl. Power Electron. Conf. (APEC), 2008, pp. 682-688.

[5] S. Michelis, F. Faccio, P. Jarron, and M. Kayal, "Air core inductors study for dc-dc power supply in harsh radiation environment," in Proc. IEEE North-East Workshop Circuits Syst. (NEWCAS)-TAISA Conf., 2008, pp. $105-108$.

[6] J. Yunas, N. A. Rahman, L. T. Chai, and B. Y. Majlis, "Study of coreless planar inductor at high operating frequency," in Proc. IEEE Int. Conf. Semicond. Electron. (ICSE), 2004, pp. 606-610.

[7] O. Reilly, M. Duffy, T. O. Donnell, S. C. Ó Mathúna, M. Scott, N. Young, and S. Payne, "Integration of a range of RF chip inductors in advanced printed circuit board technology," in Proc. (Int. Microelectron. Packag. Soc. (IMAPS), 1999, pp. 363-369.

[8] C. Marxgut, J. Biela, and J. W. Kolar, "Design of a multi-cell, DCM PFC rectifier for a $1 \mathrm{~mm}$ thick, $200 \mathrm{~W}$ off-line power supply-The power 
sheet," presented at the Conf. on Integrated Power Electron. Syst. (CIPS), Nuremberg, Germany, 2010.

[9] C. Marxgut, J. Biela, and J. W. Kolar, "Interleaved triangular current mode (TCM) resonant transition, single phase PFC rectifier with high efficiency and high power density," in Proc. Power Electron. Conf., 2010, pp. 17251732.

[10] B. Allongue, G. Blanchot, C. Fuentes, F. Faccio, S. Michelis, and S. Orlandi, "System integration issues of dc to dc converters in the sLHC trackers," in Proc. Nuclear Sci. Symp. (NSS), 2009.

[11] T. Simpson, "Effect of a conducting shield on the inductance of an air-core solenoid," IEEE Trans. Magn., vol. 35, no. 1, pp. 508-515, Jan. 1999.

[12] S. C. Tang, S. Y. R. Hui, and H. Chung, "Evaluation of the shielding effects on printed-circuit-board transformers using ferrite plates," in Proc. Power Electron. Specialists Conf. (PESC), 2000, vol. 4, pp. 1919-1925.

[13] B. Allongue, F. Anghinolfi, G. Blanchot, C. Fuentes, F. Faccio, S. Michelis, S. Orlandi, and A. Toro, "Noise susceptibility measurements of front-end electronics systems," presented at the Topical Workshop on Electron. for Particle Phys., Naxos, Greece, 2008.

[14] O. Dezuari, S. E. Gilbert, E. Belloy, and M. A. M. Gijs, "Development of a novel printed circuit board technology for inductive device applications," Sens. Actuators A: Physical, vol. 76, no. 1-3, pp. 349-355, Aug. 30, 1999.

[15] W. A. Roshen, C. S. Korman, and W. Daum, "High density interconnect embedded magnetics for integrated power," IEEE Trans. Power Electron., vol. 21, no. 4, pp. 867-880, Jul. 2006.

[16] W. A. Roshen, "High-efficiency, high-density MHz magnetic components for low profile converters," IEEE Trans. Ind. Appl., vol. 31, no. 4, pp. 869877, Jul./Aug. 1995.

[17] J. W. Phinney, J. H. Lang, and D. J. Perreault, "Multi-resonant microfabricated inductors and transformers," in Proc. Power Electron. Specialists Conf. (PESC), 2004, pp. 4527-4536.

[18] T. C. Neugebauer and D. J. Perreault, "Parasitic capacitance cancellation in filter inductors," in Proc. Power Electron. Specialists Conf. (PESC), 2004, pp. 3102-3107.

[19] O. Reilly, M. Duffy, S. C. Ó. Mathúna, and S. Payne, "Routes to embedded inductors in MCM-L technology-Design, CAD and manufacturing issues," in Proc. Int. Microelectron. Packag. Soc. (IMAPS), Nov. 1998, pp. $461-466$.

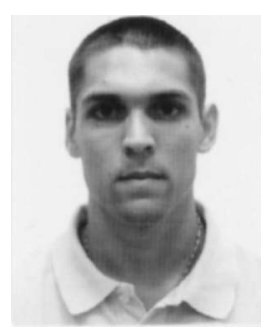

Stefano Orlandi was born in Verona, Italy, in 1983. He received the Graduate degree in electronic engineering from the University of Padova, Padova, Italy, in 2008, in the field of power electronics.

Since July 2008, he has been with the European Organization for Nuclear Research (CERN), Geneva, Switzerland. His research interests include the development of $\mathrm{dc}-\mathrm{dc}$ converters to distribute power to the electronics of the Large Hadron Collider upgrade. He has performed electromagnetic simulations and integrated circuit design. on air-core inductors, as well as circuit simulations

Bruno Andre Allongue, photograph and biography not available at the time of publication.

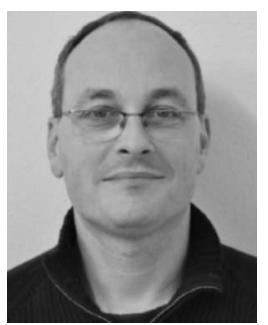

Georges Blanchot graduated in industrial engineering in Brussels, Belgium, in 1991. He obtained a Master of Advanced Studies degree in electronics instrumentation in 1992, and a Physics Instrumentation Master degree in 1993 at the Catholic University of Louvain (UCL), Belgium.

He has been involved in astrophysics and particle physics front-end electronics developments since 1994, working at IFAE in Barcelona, Spain. He joined the Front-End Electronics Group of the Physics Department at the European Centre for Nuclear Research (CERN) in 2004, where he participates in the development of different front-end systems for the CERN experiments. He provides also expertise and support in electromagnetic compatibility. He is now involved in the development of low noise dc-dc converter modules using the radiation and magnetic field tolerant power ASICs developed at CERN, aiming for the electromagnetic compatibility between the converters and the front-end systems that they power.

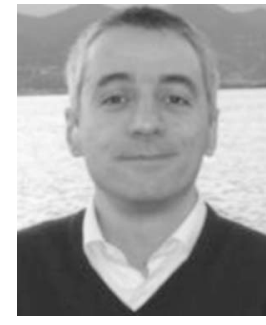

Simone Buso (M'97) received the M.Sc. degree in electronic engineering and the Ph.D. degree in industrial electronics from the University of Padova, Padova, Italy, in 1992 and 1997, respectively.

$\mathrm{He}$ is currently an Associate Professor of electronics with the Department of Technology and Management of Industrial Systems (DTG), University of Padova. His main research interests are in the industrial and power electronics fields and are specifically related to $\mathrm{dc}-\mathrm{dc}$ and ac/dc converters, digital control able energy sources. of power converters, solid-state lighting, and renew-

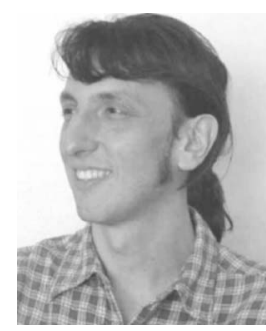

Federico Faccio received the M.S. degree in physics from the University of Turin, Italy, in 1991, and the $\mathrm{Ph} . D$. degree from the National Polytechnic Institute, Grenoble, France, in 1997.

He joined the Microelectronics Group at the European Centre for Nuclear Research (CERN) in 1991, where he has been mainly involved in the study of the radiation effects on semiconductor devices and technologies. As a microelectronics circuit designer, he has participated over the years in the development of different radiation-hard ASICs for the CERN experiments at the LHC accelerator: ADCs, optical receivers and data recovery circuits, linear regulators and $\mathrm{dc}-\mathrm{dc}$ converters. He is now leading an $\mathrm{R} \& \mathrm{D}$ project for the development of a radiation and magnetic field tolerant $\mathrm{dc}-\mathrm{dc}$ converter, and he is acting as senior engineer in the CERN efforts to select and qualify deep submicron CMOS technologies for use in harsh radiation environments.

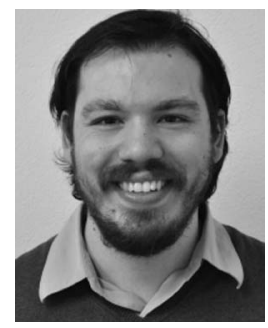

Cristian Alejandro Fuentes received the B.S. and M.S. degrees in electronic engineering from UTFSM University, Valparaíso, Chile, in 2009.

He joined the Front-End Electronics Group of the Physics Department at the European Centre for Nuclear Research (CERN) in 2008. He is actually a PhD student of UTFSM, while working at CERN on the development of low noise dc-dc converter modules using the radiation and magnetic field tolerant power ASICs developed at CERN. His current research interests include electromagnetic compatibility (EMC), EMI reduction in dc-dc converters and their integration with high-energy physics (HEP) experiments.

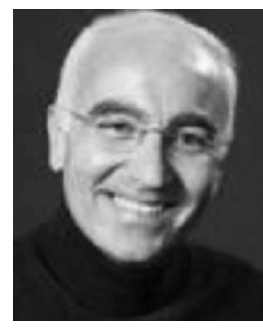

Maher Kayal was born in 1959. He obtained the Master degree and Ph.D. in electrical engineering from the Swiss Federal Institute of Technology (EPFL), in 1983 and 1989, respectively.

Since 1999, he is a professor in the electronics laboratories of the Swiss Federal Institute of Technology. He has published many scientific papers, coauthored two books, and holds three recent patents. His current research and development includes: mixed-mode circuit design, sensors interface, signal processing, and CAD tools for analog design and layout automation. 


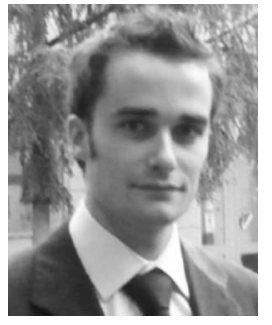

Stefano Michelis was born in Torino (Italy) in 1982 $\mathrm{He}$ received the M.S. degree in micro and nanotechnology engineering for IC from the Politecnico of Turin, the Institut National Polytechnique de Grenoble (INPG) and the Ecole Polytechnique Federale de Lausanne (EPFL) with distinction, in September 2006. He is pursuing the Ph.D. degree in Microsystems and Microelectronics at the EPFL.

He did his master project at the European Organization for Nuclear Research (CERN) in Geneva, in the Microsystems Department (PH/MIC) in collaboration with Electronics Laboratory of EPFL on a new low voltage power distribution scheme for the upgrade of the Large Handron Collider (LHC). He is working in the development of a radiation tolerant, high frequency dc-dc converter for LHC experiments.

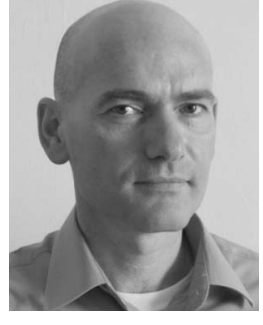

Giorgio Spiazzi (S'92-M'95) graduated cum laude in electronic engineering from the University of Padova in 1988. In 1993, he took his Ph.D. in industrial electronics.

$\mathrm{He}$ is currently working as an associate professor in the Department of Information Engineering (DEI) of the University of Padova, Italy. His main research interests are in the fields of power factor correctors, soft-switching techniques, lamp ballasts, renewable energy applications, and electromagnetic compatibility in power electronics. 